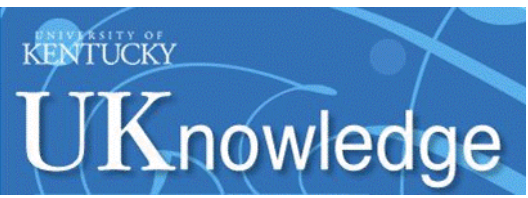

University of Kentucky

UKnowledge

Spring 2011

\title{
RDA: Resource Description and Access
}

\author{
Kathryn Lybarger \\ University of Kentucky, kathryn.lybarger@uky.edu
}

Follow this and additional works at: https://uknowledge.uky.edu/libraries_present

Part of the Library and Information Science Commons

Right click to open a feedback form in a new tab to let us know how this document benefits you.

\section{Repository Citation}

Lybarger, Kathryn, "RDA: Resource Description and Access" (2011). Library Presentations. 17.

https://uknowledge.uky.edu/libraries_present/17

This Presentation is brought to you for free and open access by the University of Kentucky Libraries at UKnowledge. It has been accepted for inclusion in Library Presentations by an authorized administrator of UKnowledge. For more information, please contact UKnowledge@lsv.uky.edu. 
Guest Lecture

LIS 656, Spring 2011 Kathryn Lybarger

\section{RDA: RESOURCE DESCRIPTION AND ACCESS}




\section{RDA example}

020

\$a 9781401323165

040 \$a KUK \$c KUK \$e rda

1001 _ \$a Miss Piggy, \$e author.

24514 \$a The Diva Code / \$c Miss Piggy.

250 — \$a First Edition.

260 _a New York : \$b Hyperion Books,

$\$ c$ [date of publication not identified], (02009.

$300 \_$_a xii, 126 pages : \$b illustrations ;

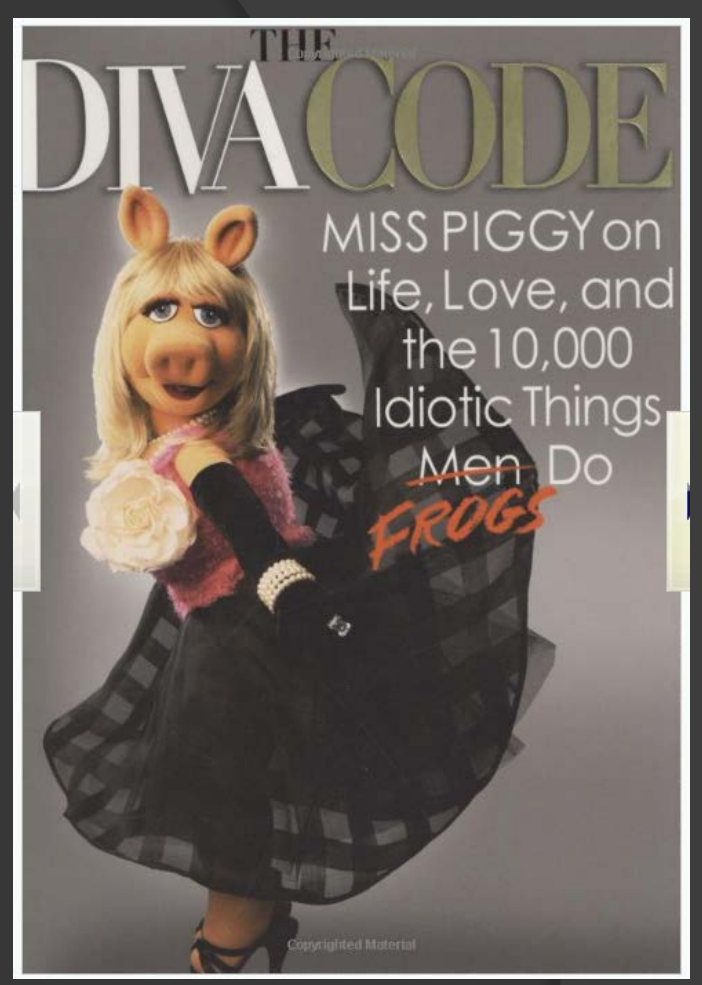

$\$ \mathrm{c} 20 \mathrm{~cm}$

336 — \$a text $\$ 2$ rdacontent

337 —a unmediated $\$ 2$ rdamedia

338 _ $\$$ a volume $\$ 2$ rdacarrier

$650 \_0 \$$ a Conduct of life $\$ v$ Humor.

650 0 \$a Man-woman relationships \$v Humor.

7101 1_\$a Lewis, Jim, \$d 1952- \$e transcriber. 


\section{What is RDA?}

(0) "RDA provides a set of guidelines and instructions on formulating data to support resource discovery. RDA provides a comprehensive set of guidelines and instructions covering all types of content and media."

--Joint Steering Committee for

Development of RDA 


\section{Joint Steering Committee}

o The American Library Association

○ The Australian Committee on Cataloguing

o The British Library

○ The Canadian Committee on Cataloguing

○ CILIP: Chartered Institute of Library and Information Professionals

o The Library of Congress 


\section{RDA Toolkit}

○ Released June 2010

๑ Online resource, subscription

- http://www.rdatoolkit.org

○ Published in the US by ALA

o Snapshots are available in hard copy (no updates) 


\section{RDA Toolkit contents}

○ Extensive documentation on RDA

( ) Links to equivalents in AACR2

o Library of Congress Policy Statements (LCPS)

○ Workflows

- Including user-submitted 


\section{RDA Timeline / Status}

○ US test period

- October - December 2010

- 26 libraries testing

( ) Analysis

- First half of 2011

- Should US national libraries adopt?

o Announcement

- ALA annual meeting? 


\section{RDA records in OCLC}

( ) 17000 RDA records in OCLC

- Command line search: dx:rda ti:science

○ Some test libraries (Chicago) now do all original cataloging in RDA

○ OCLC does not want parallel records

( ) Regardless of decision, we should be familiar with the RDA standard 


\section{RDA is a content standard}

○ RDA records need not be encoded in MARC

o RDA defines data elements (such as "title proper"), attributes and relationships

○ Most RDA is currently done in MARC 


\section{Differences between RDA and}

AACR2

○ Many RDA rules are simpler

o Many RDA rules allow more cataloger judgment

(0 "Take what you see" and "accept what you get" 


\section{RDA description}

○ In theory, RDA description is much different from AACR2 


\section{Functional Requirements for \\ Bibliographic Records}

○ FRBR - pronounced spelled out, or "Fur-bur".

○ Entity-relationship model

o Similar standards FRAD (authority) and FRSAD (subject authority, upcoming) 


\section{FRBR tasks}

( ) Find

- Bring up materials that match search

( ) Identify

- Distinguish between, confirm match

( ) Select

- Technical requirements, intellectual value

( ) Obtain

- Access the resource 


\section{FRBR entities}

○ Group 1 - products of intellectual or artistic endeavor

- Work, expression, manifestation, item

o Group 2 - those responsible for Group 1 content

- Person, corporate body, family

○ Group 3 - subjects for Group 1

- Concept, object, event, place 
Relationships (Group 1 example)

Work

Expression

Manifestation

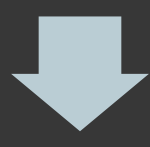

Item is realized through

is embodied in

is exemplified by 


\section{Relationships (Group 2 example)}

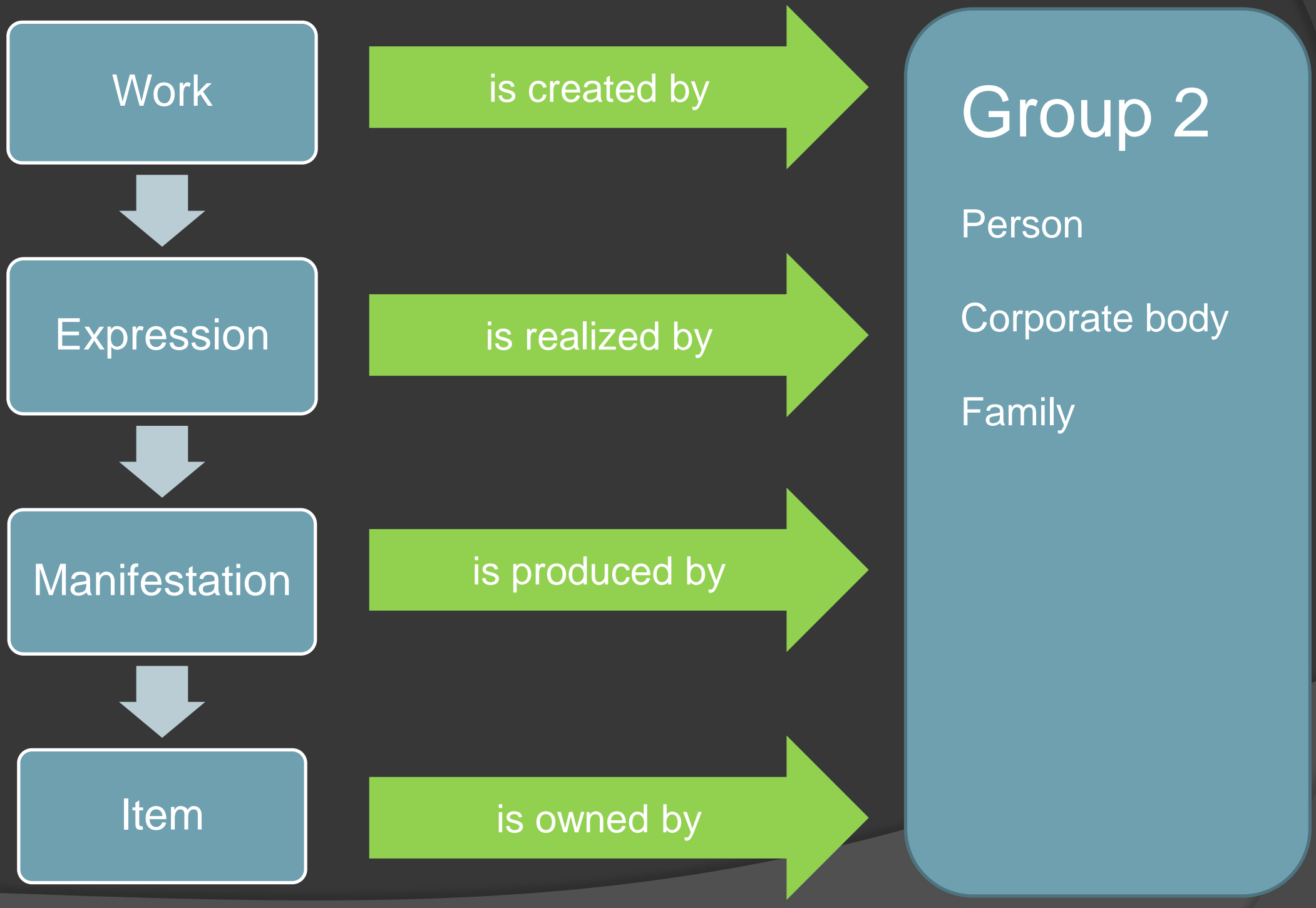


Relationships (Group 3 example)

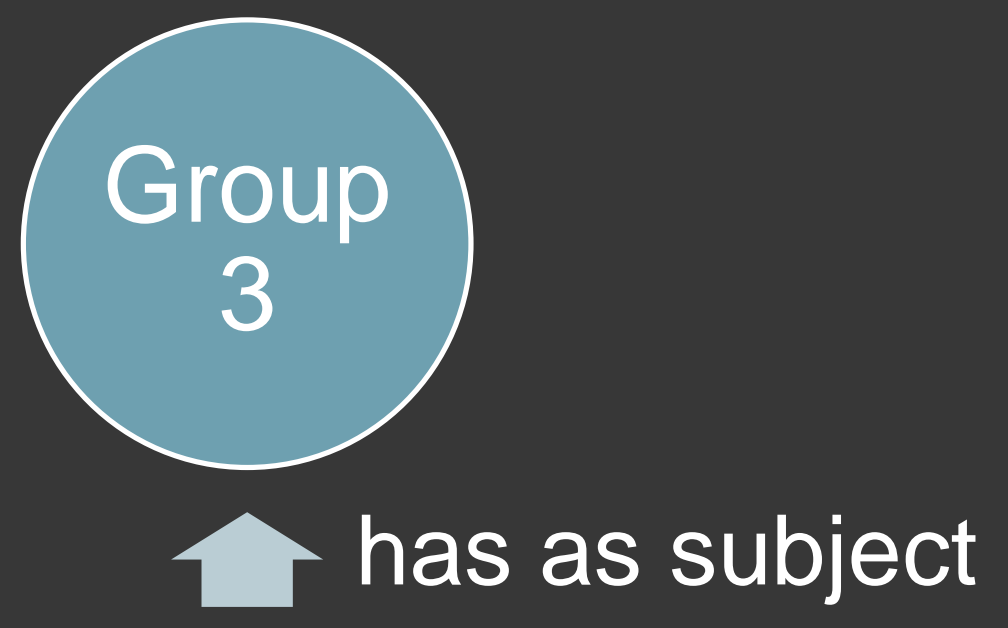

has as subject Work has as subject

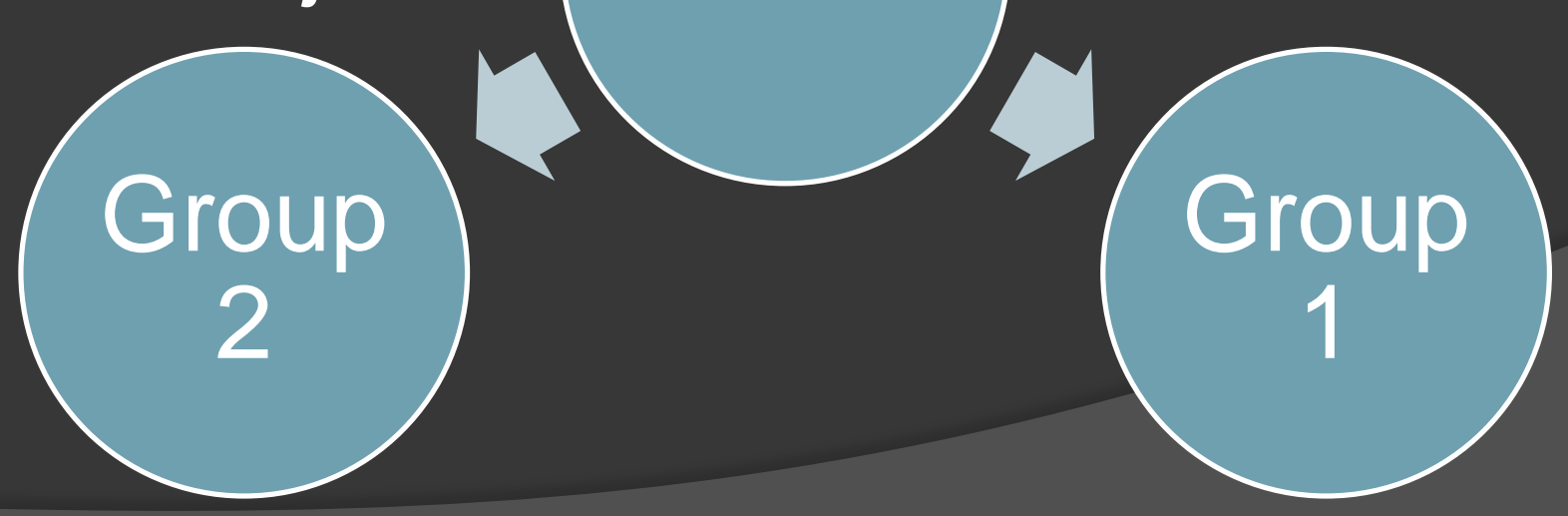




\section{Attributes}

o Entities have attributes for which you record values

o Example:

- Work has attribute Title for which you might record the value "The Cat in the Hat"

- Person has attribute Name for which you might record the value "Gaiman, Neil"

- Subject has attribute Term for which you might record the value "Boxer (Dog breed)" 
RDA is based on FRBR

\section{FRBR attributes}

RDA elements 


\section{Core / Core If (examples)}

○ Title

- Title proper

○ Statement of responsibility

○ Edition statement

○ Numbering of serials 


\section{Core / Core If (examples)}

๑ Publication statement

○ Distribution statement

- IF publication info lacking

○ Manufacture statement

- IF publication and distribution info lacking 


\section{LC Core}

○ Library of Congress recommended additions to Core / Core If

o Example:

- Other title information (245 \$b)

- Parallel title (245 \$b) 
AACR2/ISBD Areas of

Bibliographic Description

1. Title and statement of responsibility

2. Edition

3. Material-specific details

4. Publication, distribution

5. Physical description

6. Series

7. Notes

8. Standard number/terms of availability 


\section{Identifying a work}

○ What makes this work unique?

- Title

- Creator

○ Different works:

- The invisible man / H.G. Wells.

- Invisible man / Ralph Ellison. 


\section{Identifying an expression}

○ What makes this expression unique?

- Language

- Content type

- Spoken word

- Performed music

o Different expressions:

- Nation / Terry Pratchett. (printed book)

- Nation / Terry Pratchett (audiobook) 


\section{Identifying a manifestation}

○ What makes this manifestation unique?

- Edition statement

- Publication statement

- Carrier type

( ) Different manifestations:

- Iron man (the film on DVD)

- Iron man (the film on Blu-Ray)

o In AACR2, we typically catalog at this level 


\section{Identifying an item}

○ What makes this item unique?

- Local barcode

- Any other local distinction

○ Different items

- The crow, soundtrack on CD (my copy)

- The crow, soundtrack on CD (your copy)

○ ILS's allow cataloging at this level 


\section{RDA MARC records}

o In practice, they look very similar to AACR2 MARC records

○ Things that will stand out:

- 040 \$e rda

- 33X fields

- Abbreviations spelled out 


\section{No more Rule of Three}

○ 24510 Oriented matroids / \$c by Anders Björner, Michel Las Vergnas, Bernd Sturmfels and Neil White.

○ 24510 Oriented matroids / \$c by Anders Björner [and 4 others].

○ Those four others could have 700's or not. 


\section{Titles of Nobilty, Rank, etc. in Statement of Responsibility}

○ 24510 Army life / \$c Capt. Fred Jones.

○ 24514 The art of soul winning / \$c by J.W. Mahood, evangelist. 


\section{Transcribe symbols}

○ Most notably, the copyright symbol @

260 _London : \$b Springer, \$c 2010, (C)2010.

○ If you cannot type this, you may spell out "copyright" 


\section{Capitalization}

○ Capitalization is not considered important, as it does not affect searching.

○ 24514 The end / \$c by Lemony Snicket

○ 24514 The End / \$c By Lemony Snicket

○ 24514 THE END / \$C BY LEMONY SNICKET 


\section{Transcribe typos}

( ) Monographs:

- 24510 \$a Sciecne fun!

- 246 1_\$i Corrected Title: \$a Science fun!

( ) Continuing resources:

- 24510 \$a Science news

- 500 _ \$a Title on first volume: Sciecne news

○ Transcribe typos, but note if important 


\section{Transcribe lies!}

( ) Transcribe what is on the piece, even if you know it not to be true.

o Fictional characters may now be main entries.

o Make a note if it seems important. 


\section{Abbreviations}

( Common abbreviations spelled out

- pages, colour illustrations

○ Latin abbreviations replaced

- S.I. $\rightarrow$ [Place of publication not identified]

- s.n. $\rightarrow$ [Publisher not identified]

- ca. $\rightarrow$ approximately

- et. al. $\rightarrow$ [and 11 others] 


\section{Exceptional abbreviations}

๑ " $\mathrm{cm}$ " is a symbol, not an abbreviation

○ $300 \_x i, 200$ pages ; \$b illustrations ; $\$ \mathrm{c} 3 \overline{0 \mathrm{~cm}}$

\section{(note there is NO period at the end)}

○ "in.", "ft.", "min.", "sec." are still acceptable abbreviations 


\section{Edition statement}

○ Transcribe edition statement as it appears on the piece

( $) 250 \_$FIRST EDITION.

( ) 250 _ 2nd edition, revised.

○ $250 \_$_ 3 d ed..

○ (that final period is ISBD punctuation) 


\section{No more GMD (245 \$h)}

\section{○ These will be harder to distinguish (in current ILS)}

4 Gone with the wind / [by] Margaret Mitchell; with an introduction by James A. Michener.

Mitchell, Margaret, 1900-1949.

1977

PS3525.1972 G60 1975

$\checkmark$ available, Young Library - 5th Floor

$5 \quad B$ Gone with the wind [videorecording]

1998

AV-V2498

multiple items available, Young Media Library

6 Gone with the wind [videorecording] / a Selznick International Picture in association with Metro Goldwyn Mayer.

2009

AV-D2498

multiple items available, Young Media Library 
336: Content type

( ) Form of communication through which the work is expressed

( ) Examples:

- 336 _ text $\$ 2$ rdacontent

- 336 _ performed music $\$ 2$ rdacontent

- 336 _ cartographic three-dimensional form $\$ 2$ rdacontent 
337: Media type

o General type of intermediation device required to view, play, run the resource

○ Examples:

- 337 _ unmediated $\$ 2$ rdamedia

- 337 _ audio $\$ 2$ rdamedia

- 337 _ microscopic $\$ 2$ rdamedia 
338: Carrier type

○ The format of the storage medium and housing of a carrier

o Examples:

- 338 _ volume $\$ 2$ rdacarrier

- 338 _ videodisc $\$ 2$ rdacarrier

- 338 _ online resource $\$ 2$ rdacarrier 
$33 X$ are repeatable

○ For a streaming radio station with both music and talk radio, you could use:

336 _ performed music $\$ 2$ rdacontent

336 _ spoken word \$2 rdacontent

337 _ audio \$rdacontent

338 _ sound recording \$rdacontent

338 _ electronic resource \$rdacontent 


\section{X specific enough?}

○ 338 _ videodisc $\$ 2$ rdacarrier

○ Could refer to:

- DVD (any region)

- Blu-Ray

- HD-DVD

( Specific format may go into 300 or notes. 


\section{Access points}

○ Access points need not be justified

o RDA encourages the use of relator terms or codes to indicate relationships

○ http://www.loc.gov/marc/relators/ 


\section{Relator terms / codes}

○ 710 1_Adams, Ansel, \$d 1902-1984, \$e photographer.

○ 7101 1_Nabokov, Vladimir Vladimirovich, $\$ d$ 1899-1977, \$e translator.

○ 710 1_Adams, Ansel, \$d 1902-1984. \$4 pht

○ 7101 Nabokov, Vladimir Vladimirovich, \$d 18999-1977. \$4 trl 


\section{Authority}

( ) Many new authority MARC fields:

- 370 - Associated Place

- 371 - Address

- 372 - Field of Activity

- 373 - Affiliation

- 374 - Occupation

- 375 - Gender

- 376 - Family Information

- 377 - Associated Language 


\section{RDA at University of Kentucky}

○ All original cataloging still in AACR2

○ Accept RDA copy with few modifications

- Less than 100 so far

○ Make valid changes for consistency

- Capitalization

- Notes

○ Include GMD if appropriate

- (not true valid RDA records) 